substances from impacted neutrophils in the lungs. Since polyacrylonitrile membrane dialysers also activate complement but do not cause appreciable leucopenia, ${ }^{3}$ it is more likely that the mechanism implicated in our patient was pulmonary leucostasis.

There are several other unexplained complications of dialysis which might be related to complement activation or leucostasis or both. They include arthralgia, abdominal discomfort, migraine, and ascites. Trials of polyacrylonitrile membrane (avoiding neutropenia) or polycarbonate membrane (avoiding complement activation) would seem worthwhile in these conditions.

We thank Dr R A L Brewis for his help and advice in the management of the patient. Dr P Aljama was supported by the Foundation March, and Dr P Brown by the Northern Regional Health Authority.

${ }^{1}$ Craddock, P R, et al, New England fournal of Medicine, 1977, 296, 769

${ }^{2}$ Hendrick, D J, and Lane, D J, British Medical fournal, 1977, 1, 607.

${ }^{3}$ Aljama, P, et al, Dialysis and Transplantation, 1978, 7, 334.

${ }^{4}$ Lancet, 1975, 2, 691.

(Accepted 30 March 1978)

Department of Medicine, Royal Victoria Infirmary, Newcastle upon Tyne NE1 4LP

$P$ ALJAMA, LMS, MD, research associate

$P$ BROWN, $M B, M R C P$, regional research registrar, respiratory diseases

$P$ TURNER, MB, MRCP, senior registrar

$M \mathrm{~K}$ WARD, MB, MRCP, lecturer in medicine

D N S KERR, MSC, FRCP, professor of medicine

\section{Osmotic fragility of erythrocytes in Duchenne muscular dystrophy}

Duchenne muscular dystrophy is an $\mathrm{X}$-linked recessive disorder affecting young boys. It is one of the more severe forms of muscular dystrophy and is transmitted by healthy female carriers. Onset is usually at 3-5 years and affected individuals become chairbound by the end of the first decade. Death occurs in the late teens or early twenties from cardiac failure or pneumonia. The basic defect in this disorder is as yet unknown but several recent studies ${ }^{1-4}$ have suggested that there may be a generalised membrane abnormality affecting erythrocytes as well as muscle. Fisher et $a^{4}$ have reported an increase in the osmotic fragility in cases of what they refer to as "pseudohypertrophic muscular dystrophy." We report here our findings in a series of 10 patients with confirmed Duchenne muscular dystrophy and four definite carriers. (A definite carrier is defined as the mother of an affected boy with another affected male relative. The four carriers studied here had serum creatinine kinase levels of 83,132 , 213, and $344 \mathrm{IU} / 1$ (normal upper limit $85 \mathrm{IU} / 1$ ).)

\section{Patients, methods, and results}

Heparinised samples of venous blood were obtained from patients (aged 1-18), their unaffected brothers (aged 1-16), and female carriers (aged 23-56) when the families attended the muscular dystrophy clinic in the department. Control samples were obtained from young boys (aged 4-15) before ortho-

Per cent lysis (mean $\pm S D$ ) in male controls, boys with Duchenne muscular dystrophy (DMD), their unaffected brothers, female controls, and definite carriers

\begin{tabular}{|c|c|c|c|c|c|}
\hline $\begin{array}{c}\text { Sodium } \\
\text { chloride } \\
\text { concentration } \\
(\mathrm{g} / 1)\end{array}$ & $\begin{array}{c}\text { Male } \\
\text { controls } \\
(\mathrm{n}=10)\end{array}$ & $\begin{array}{l}\text { DMD } \\
\text { patients } \\
(\mathrm{n}=10)\end{array}$ & $\begin{array}{l}\text { Brothers } \\
(\mathrm{n}=5)\end{array}$ & $\begin{array}{l}\text { Female } \\
\text { controls } \\
(\mathrm{n}=36)\end{array}$ & $\begin{array}{l}\text { Definite } \\
\text { carriers } \\
(n=4)\end{array}$ \\
\hline $\begin{array}{l}1 \cdot 0 \\
3 \cdot 6 \\
3 \cdot 8 \\
4 \cdot 0 \\
4 \cdot 2 \\
4 \cdot 4 \\
4 \cdot 6 \\
4 \cdot 8 \\
5 \cdot 0\end{array}$ & $\begin{array}{c}100 \\
95 \cdot 1=2.9 \\
90 \cdot 7: 3 \cdot 0 \\
79 \cdot 4: 12.5 \\
50.7 \pm 17.6 \\
13.9 \pm 9.9 \\
4.5 \pm 4 \cdot 2 \\
1.7 \pm 1.8 \\
0 \cdot 0\end{array}$ & $\begin{array}{c}100 \\
94 \cdot 4: 5 \cdot 9 \\
91 \cdot 2 \cdot 7 \cdot 2 \\
83 \cdot 4: 13 \cdot 6 \\
66 \cdot 7: 18 \cdot 3 \\
34 \cdot 0 \cdot 19 \cdot 6 \\
16 \cdot 3 \cdot 13 \cdot 0 \\
6 \cdot 9=7 \cdot 0 \\
1 \cdot 3 \\
1 \cdot 5\end{array}$ & $\begin{array}{c}100 \\
93 \cdot 4 \pm 6 \cdot 0 \\
83 \cdot 4 \pm 13 \cdot 2 \\
63 \cdot 6=18 \cdot 3 \\
38 \cdot 5=11 \cdot 9 \\
9 \cdot 5=2 \cdot 1 \\
4 \cdot 6 \pm 2 \cdot 1 \\
1 \cdot 3 \pm 0 \cdot 7 \\
0 \cdot 0\end{array}$ & $\begin{array}{c}100 \\
95 \cdot 5=3 \cdot 6 \\
89 \cdot 9=8 \cdot 5 \\
78 \cdot 8=14 \cdot 4 \\
64 \cdot 4: 18 \cdot 1 \\
40 \cdot 4=17 \cdot 7 \\
18 \cdot 6: 11 \cdot 3 \\
6 \cdot 8=6 \cdot 7 \\
1 \cdot 2: 1 \cdot 9\end{array}$ & $\begin{array}{c}100 \\
91 \cdot 6 \pm 2 \cdot 8 \\
86 \cdot 5 \div 3 \cdot 5 \\
75 \cdot 7=11 \cdot 7 \\
49 \cdot 5=20 \cdot 1 \\
18 \cdot 1=14 \cdot 9 \\
5 \cdot 8=7 \cdot 1 \\
2 \cdot 1 \pm 3 \cdot 3 \\
0 \cdot 0\end{array}$ \\
\hline
\end{tabular}

paedic operations for disorders unrelated to neuromuscular abnormalities and healthy women volunteers (aged 17-67). The amount of lysis at various concentrations of sodium chloride was determined by the method of Dacie and Lewis." The concentrations of sodium chloride resulting in 50 "., lysis of each sample were derived graphically.

Signs of lysis first became apparent in affected boys at a concentration of $5.0 \mathrm{~g} / \mathrm{l}$ but in the controls and normal brothers at a concentration of $4.8 \mathrm{~g} /$. At all concentrations of sodium chloride from 4.4 to $5.0 \mathrm{~g} \mathrm{l}$ (see table) there was significantly greater lysis in affected boys than in either their unaffected brothers or controls (P. 0.05). The concentration (mean \pm SD) of sodium chloride which resulted in $50^{\circ}$ ". lysis was $4 \cdot 18 \pm 0 \cdot 10 \mathrm{~g} / \mathrm{for}$ male controls, $4 \cdot 30 \pm 0 \cdot 13 \mathrm{~g} 1$ for affected boys, and $4 \cdot 08 \pm 0 \cdot 12 \mathrm{~g} 1$ for their unaffected brothers, the difference between affected boys and either their unaffected brothers or controls being statistically significant (P. 0.05). There was no difference in erythrocyte osmotic fragility between definite carriers and the control series of normal women.

\section{Comment}

These results provide additional evidence that there is a probable defect in the erythrocyte membrane in patients with Duchenne muscular dystrophy.

We thank Professor A E H Emery for his encouragement and help with this study, which was supported by the Muscular Dystrophy Group of Great Britain. Miss S Lloyd holds a Fullerton postgraduate research fellowship at the University of Edinburgh. Miss M Nunn holds a Gunning Vacation Bursary.

Kunze, D, et al, Clinica Chimica Acta, 1973, 43, 333

2 Matheson, D W, and Howland, J L, Science, 1974, 184, 165

${ }^{3}$ Mokri, B, and Engel, A G, Neurology, 1975, 25, 1111.

${ }^{4}$ Fisher, E R, et al, fournal of the American Medical Association, 1976, 236, 955.

"Dacie, J V, and Lewis, S M, Practical Haematology, 5th edn. London, Churchill Livingstone, 1975.

(Accepted 30 March 1978)

University Department of Human Genetics, Western General Hospital, Edinburgh EH4 2HU

SUSAN J LLOYD, BSC, research student

MURIEL G NUNN, medical student

\section{Endoscopic removal of a swallowed ball bearing from stomach of a 4-year-old child}

Foreign bodies commonly pass uneventfully through the gastrointestinal tract to be voided with the faeces. Thus patience and expectant treatment are usually recommended unless the size of the foreign body or its nature makes obstruction or perforation likely. ${ }^{1}$ Hitherto in these circumstances removal by rigid endoscope or operation has been undertaken, but recently reports have described removal of various objects using fibreoptic endoscopes." Grasping forceps and snares have been developed and ingenious techniques devised to retrieve objects with perforations or a waist-and even razor blades. ${ }^{3}$ We were presented with a boy who had swallowed a ball bearing, and, as a suitable device was not available, we evolved a new method.

\section{Case history}

A fit West Indian boy aged 4 swallowed a steel ball bearing. Although well, he was brought to hospital by anxious parents. The results of examination were normal but radiographs of chest and abdomen showed a dense sphere $17 \mathrm{~mm}$ in diameter in the stomach. During the next six weeks he took a normal diet and did not vomit, yet serial radiographs showed the ball still in the stomach. As there was no sign of passage beyond the pylorus surgical removal was contemplated, but before laparotomy endoscopic removal was attempted.

A standard latex contraceptive condom was attached by cotton thread to the distal end of an Olympus GIFD2 endoscope. Three equally spaced ties were passed through the condom around the rolled rim and the free ends threaded through the lumen of the rubber hood detached from the 
end of the endoscope. The hood was replaced trapping the cotton threads, which were adjusted to lie symmetrically around the circumference of the instrument tip. The ties were adjusted making a self-opening "trawl net" $5 \mathrm{~cm}$ from the tip of the endoscope (fig). The teat of the condom was tied off. A short period of practice outside the body showed the feasibility of using the device.

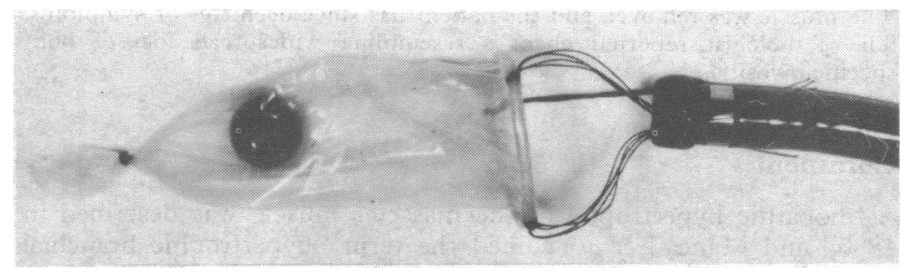

Under general anaesthetic the modified GIFD2 was introduced into the oesophagus with the condom alongside the endoscope, which was advanced to the gastric antrum, where the ball bearing was located. The condom was brought into view by withdrawing the instrument about $5-10 \mathrm{~cm}$. Within a few minutes the ball was rolled into the condom by tipping the child. The whole was withdrawn into the oesophagus, although the ball was held up at the level of the cuffed endotracheal tube, deflation of which allowed delivery. Re-examination of the proximal gastrointestinal tract showed no abnormality apart from erythema of the prepyloric mucosa; the pylorus was not.narrowed. The removed ball bearing had a sulphurous smell and was black with a pitted surface. The child was allowed home on the next day.

\section{Comment}

Fibreoptic endoscopes are widely used as safe diagnostic aids and are employed for a growing number of therapeutic procedures. Available accessories permit removal of a variety of foreign bodies: we have recovered coins, a medallion, needles, a spoon a bottle top, a dental plate, and a clinical thermometer without difficulty or complication. With special adjuncts, as here described, some unusual objects may be retrieved. The success and safety of such techniques suggest that the traditional "wait and see" policy may be challenged. Immediate recovery of objects whose safety or ultimate passage is doubtful may save patients and their attendants much time and worry, and would reduce costly periods of observation and exposure to diagnostic radiology. It is, however, appropriate to recommend caution lest overenthusiastic interference or inexpert technique damages the patient. Sharp objects embedded into the wall of the gastrointestinal tract or those which may traumatise the gut during removal are still better treated surgically.

${ }^{1}$ Spitz, L, British Medical fournal, 1971, 4, 469.

Schiller, K F R, and Salmon, P R, Gut, 1973, 14, 920

3 Witzel, L, et al, British Medical fournal, 1974, 2, 539.

(Accepted 30 March 1978)

Selly Oak Hospital, Birmingham B29 6JD

C WREN, MB, CHB, house physician (present address: Kidderminster General Hospital Kidderminster, Worcestershire)

R COCKEL, MA, MRCP, consultant physician

\section{Circadian variation in an immune response in man}

We recently showed the circadian rhythm of the immune response in the skin to challenge with oxazolone in oxazolone-sensitised rats. ${ }^{1}$ Others have shown that renal transplant survival in rats varies with the time of transplantation. ${ }^{2}$ Circadian variations have been observed in the responses of human lymphocytes to mitogen stimulation, ${ }^{3}$ but results are conflicting and may depend on whether whole blood or isolated lymphocytes are used in the assay. ${ }^{1}$ There is little information about circadian variations in human immune responses in vivo.

The response to intradermal tuberculin is a typical example of cellmediated immunity: $70 \%$ of the cells present in the lesion at 48 hours are mononuclear cells, predominantly lymphocytes. Intra- dermal injection of purified protein derivative of tuberculin (PPD) to a standard depth (Heaf test) was used to study the response to challenge at different times of day.

\section{Methods}

Healthy nurses and medical students $(n=180)$ aged 17-21 were divided into seven groups, and Heaf tests were performed at 0100, 0400, 0700, 1000, 1300,1600 , and 2200 . Tests in those studied at 0100 and 2200 were repeated at 0700 seven weeks later. After this interval interference from the first test was unlikely. The responses were assessed independently by two observers exactly 48 hours after the tests. The area of induration was traced and magnified $(\times 3.4)$ on to squared paper. Results were expressed as the mean $\left( \pm S E\right.$ of mean) raised area $\left(\mathrm{mm}^{2}\right)$. Comparisons were made with the appropriate $t$ test, with non-responders excluded except in the paired $t$ test.

Altogether 122 subjects $(68 \%)$ had a measurable response. The two observers' assessments were similar $(r=0.86 ; y=1.03 x+2.60 ; P<0.001)$. The figure shows the magnitude of the response at 48 hours plotted against time of challenge with PPD, together with the circadian rhythm of plasma 11-hydroxycorticosteroid (11-OHCS) concentrations found previously in a different group of healthy subjects. ${ }^{4}$ Circadian variations in the skin response were evident, the maximum response at 0700 and the minimum at 2200 being significantly different $(P<0.025)$. Eighteen subjects completed the second assessment. The increase in magnitude of response to the repeat test at 0700 was significant $(P<0.01$, paired $t$ test) when compared with the initial test at either 2200 or 0100 .

\section{Comment}

An inverse relationship has been observed between plasma glucocorticoid concentrations and blood lymphocyte counts, ${ }^{3}$ and exogenous corticosteroids influence lymphocyte function and activity. The temporal patterns of plasma 11-OHCS and the skin response to PPD are similar (see figure) but this does not prove a causal relationship. Variation in lymphocyte numbers and type, their localisation at the challenge site, local inflammatory responses, and other factors may occur independent of steroid activity, but they contribute to the observed circadian variation of the immune response.

In contrast to the maximum cell-mediated response to PPD which we observed at 0700 , the antibody release induced by the cutaneous injection of allergens produced maximum response around 2300, which is the peak time for skin sensitivity to histamine. ${ }^{5}$ This suggests that the variations observed in the present study were not due simply to circadian variations in skin responsiveness locally.

The progressive increase in response to PPD given at night suggests that the immune reaction becomes more vigorous as the night proceeds, with the maximum tissue response around the time of waking.

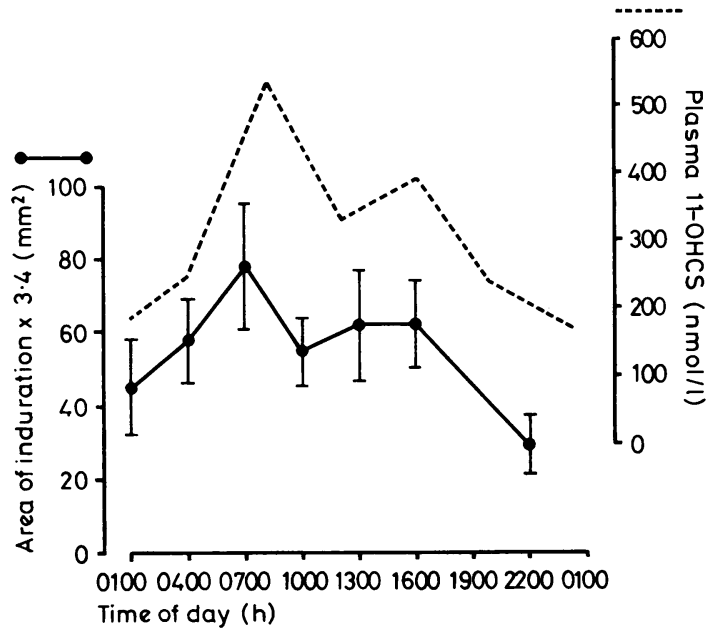

Circadian variation in immune response to tuberculin (PPD). Subjects were nurses and medical students aged 17-21 years. Solid circles represent mean ( \pm SE of mean) areas $\left(\mathrm{mm}^{2}\right)$ of induration $(\times 3.4)$ measured by two independent observers 48 hours after the injection of PPD with the Heaf gun at various times. The interrupted line represents the mean plasma 11-hydroxycorticosteroid (11-OHCS) level along a 24-hour span determined in an earlier study. ${ }^{4}$

Conversion: SI to traditional units-11-OHCS: $1 \mathrm{nmol} / 1$ $\approx 0.036 \mu \mathrm{g} / 100 \mathrm{ml}$. 